Hydrogen--deuterium exchange in KD2PO4

S. O. Kucheyev, T. E. Felter, W. J. Siekhaus, A. J. Nelson, A. V. Hamza

November 4, 2003

Applied Physics Letters 
This document was prepared as an account of work sponsored by an agency of the United States Government. Neither the United States Government nor the University of California nor any of their employees, makes any warranty, express or implied, or assumes any legal liability or responsibility for the accuracy, completeness, or usefulness of any information, apparatus, product, or process disclosed, or represents that its use would not infringe privately owned rights. Reference herein to any specific commercial product, process, or service by trade name, trademark, manufacturer, or otherwise, does not necessarily constitute or imply its endorsement, recommendation, or favoring by the United States Government or the University of California. The views and opinions of authors expressed herein do not necessarily state or reflect those of the United States Government or the University of California, and shall not be used for advertising or product endorsement purposes. 


\title{
Hydrogen-deuterium exchange in $\mathrm{KD}_{2} \mathrm{PO}_{4}$
}

\author{
S. O. Kucheyev, T. E. Felter, W. J. Siekhaus, A. J. Nelson, and A. V. Hamza \\ Lawrence Livermore National Laboratory, Livermore, California 94550
}

\begin{abstract}
Depth profiles of ${ }^{1} \mathrm{H}$ and ${ }^{2} \mathrm{D}$ in rapidly-grown $\mathrm{KD}_{2 x} \mathrm{H}_{2(1-x)} \mathrm{PO}_{4}$ (DKDP) single crystals are studied by elastic recoil detection analysis. Results show that, at ambient conditions, deuteration in the first $\sim 500 \mathrm{~nm}$ from the sample surface significantly decreases within the first several days after $\mathrm{D}_{2} \mathrm{O}$ surface polishing. This effect is attributed to the deuterium-hydrogen exchange. The effective diffusion coefficient of this process is strongly dependent on both the degree of deuteration and sample growth conditions. Physical mechanisms of the D/H exchange are discussed.
\end{abstract}

PACS numbers: 77.84.Fa, 68.49.Sf, 68.35.Pv, 42.70.Mp

Single-crystal KDP $\left(\mathrm{KH}_{2} \mathrm{PO}_{4}\right)$ and its deuterated form DKDP $\left(\mathrm{KD}_{2 x} \mathrm{H}_{2(1-x)} \mathrm{PO}_{4}\right)$ are hydrogen-bonded ferroelectrics finding important applications as light frequency converters and Pockels cells. ${ }^{1}$ Significant interest in the growth and processing of KDP and DKDP crystals has been stimulated by their use in large-aperture laser systems. Indeed, KDP and DKDP are materials of the current choice for large-aperture lasers since these crystals can be conveniently grown with linear dimensions in the range of $50-100 \mathrm{~cm} .^{2}$ However, there are a number of challenges with the growth and processing of these crystals. In particular, it has recently been observed that DKDP crystals tend to age at ambient conditions, resulting in the development of surface cracks. ${ }^{3}$ Such surface cracking has been attributed to deleterious effects of the diffusion-limited $\mathrm{D} / \mathrm{H}$ exchange and an associated buildup of tensile stress in near-surface layers, ${ }^{4}$ as suggested by Raman spectroscopy studies. ${ }^{3,5}$

In this letter, we study the surface stoichiometry of DKDP. We use elastic recoil detection analysis (ERDA) ${ }^{6}$ to evaluate depth profiles of atomic concentrations of D and $\mathrm{H}$ in $\sim 500$-nm-thick near-surface layers. Our results reveal that, at ambient conditions, surface deuteration dramatically decreases during the first several days after sample polishing. These results have important implications not only for the problem of DKDP surface cracking but also for various studies of the fundamental properties of DKDP. ${ }^{7,8}$ Indeed, many analytical techniques for studying materials properties (such as x-ray absorption/emission, light reflection, cathodoluminescence, indentation, and so on) probe the near-surface layer, whose deuteration can differ significantly from its bulk value.

The $z$-cut [i.e., (001) oriented] tetragonal DKDP crystals used in this study were grown by a rapid growth method at LLNL, as described in detail elsewhere. ${ }^{2}$ For consistency, in this letter, we show results for only one representative sample of $\mathrm{KD}_{1.2} \mathrm{H}_{0.8} \mathrm{PO}_{4}$. Qualitatively similar effects were observed for the other DKDP samples studied. The $4 \mathrm{MV}$ ion accelerator (NEC, model $4 \mathrm{UH}$ ) at LLNL was used for ERDA analysis, which was done with $3 \mathrm{MeV}^{4} \mathrm{He}^{+}$ions incident at $70^{\circ}$ to the surface normal. Hydrogen and deuterium atoms were recoiled into a detector at $30^{\circ}$ relative to the incident beam direction. An $\sim 9-\mu$ m-thick carbon foil was placed in front of the

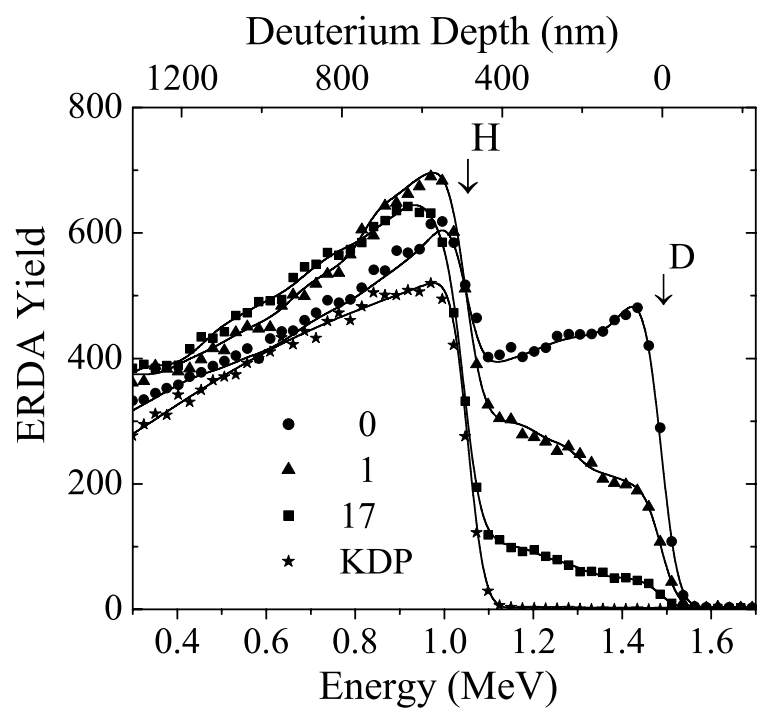

FIG. 1: Symbols: selected ERDA spectra illustrating the evolution of $\mathrm{D}$ and $\mathrm{H}$ in $\mathrm{KD}_{1.2} \mathrm{H}_{0.8} \mathrm{PO}_{4}$ stored at ambient conditions. Sample age (in days) after $\mathrm{D}_{2} \mathrm{O}$ surface polishing is indicated in the legend. The positions of the surface peaks of $\mathrm{D}$ and $\mathrm{H}$ are denoted by arrows. A spectrum taken from KDP is also shown for comparison. For clarify, only every fifteenth experimental point is depicted in spectra. Solid lines: results of RUMP simulations.

detector to stop forward scattered alpha particles. For a normal beam incidence, the circular ion beam spot on the sample surface was $\sim 6 \mathrm{~mm}$ in diameter. Ion fluence was measured with a spinning wire technique described elsewhere. ${ }^{9}$ Ion beam current was $\sim 30 \mathrm{nA}$, and the total charge of $4 \mu \mathrm{C}$ was accumulated for each ERDA spectrum. Negligible ion-beam-induced loss of $\mathrm{H}$ or D was revealed for these irradiation conditions.

Figure 1 shows selected ERDA spectra illustrating the evolution of $\mathrm{D}$ and $\mathrm{H}$ atomic concentrations in the nearsurface region of a $\mathrm{D}_{2} \mathrm{O}$-polished- $\mathrm{KD}_{1.2} \mathrm{H}_{0.8} \mathrm{PO}_{4}$ sample stored at ambient conditions for different periods. ${ }^{10} \mathrm{It}$ should be noted that DKDP samples stored in vacuum (of $\lesssim 10^{-7}$ torr) for a few days after $\mathrm{D}_{2} \mathrm{O}$ polishing show a 
negligible change in ERDA spectra. To extract the depth profiles of $\mathrm{H}$ and $\mathrm{D}$ atomic concentrations, we used the RUMP code ${ }^{11}$ to simulate ERDA spectra such as shown in Fig. 1. ${ }^{12,13}$ The absolute values of energy-dependent cross-sections for ${ }^{1} \mathrm{H}\left({ }^{4} \mathrm{He},{ }^{1} \mathrm{H}\right){ }^{4} \mathrm{He}$ and ${ }^{2} \mathrm{D}\left({ }^{4} \mathrm{He},{ }^{2} \mathrm{D}\right){ }^{4} \mathrm{He}$ forward scattering were taken from Refs. 14 and 15. In our simulations, the model sample was composed of 100 nm layers of $\mathrm{KD}_{2 x} \mathrm{H}_{2 y} \mathrm{PO}_{4}$, and the values of $x$ and $y$ (referred to below as $\mathrm{D}$ and $\mathrm{H}$ content, respectively) were found by a fitting procedure which maximized the Poisson probability function between experimental and simulated spectra. Typical examples of simulated spectra are shown in Fig. 1 by solid lines.

Figures 2(a) and 2(b) show depth profiles of $\mathrm{H}$ and $\mathrm{D}$ content, respectively, extracted from ERDA spectra. It is seen from Figs. 2(a) and 2(b) that, when DKDP is loaded into a vacuum chamber within $\sim 1$ minute after $\mathrm{D}_{2} \mathrm{O}$ polishing, it exhibits a slightly increased content of both $\mathrm{H}$ and $\mathrm{D}$ in the first $\sim 100 \mathrm{~nm}$ from the surface. ${ }^{16}$ Figures 2(a) and 2(b) also clearly illustrate that the storage of this sample at ambient conditions results in a significant decrease in $x$ and an associated increase in $y$, particularly during the first several days after $\mathrm{D}_{2} \mathrm{O}$ polishing.

The total hydrogenation (i.e., $x+y$ ) and the degree of deuteration (i.e., $x /(x+y))$ are shown in Figs. 2(c) and 2(d), respectively. It is seen from Fig. 2(c) that, for depths $\gtrsim 100 \mathrm{~nm}$, the sample remains stoichiometric (i.e., $x+y=1$ ), within experimental error, during storage at ambient conditions. However, slight variations in the total hydrogenation in the first $\sim 100$-nm-thick nearsurface layer can be seen, indicating that the total hydrogenation of this thin surface layer is affected by the water polishing and aging processes. We have also found that a linear fit to the dependence of $x$ on $y$ for all the depth profiles examined has a slope of $-0.99 \pm 0.02$ with an intercept of $1.00 \pm 0.01$. This indicates negligible changes in the total hydrogenation $(x+y)$ during aging at ambient conditions (except for the $\sim 100$-nm-thick near-surface layer discussed above), giving compelling evidence that the decrease in surface deuteration is indeed associated with the $\mathrm{D} / \mathrm{H}$ proton exchange. In this process, the layer of $\mathrm{H}_{2} \mathrm{O}$ adsorbed at the sample surface at ambient conditions acts as a source of excess hydrogen.

The time evolution of the deuteration degree for layers at different depths from the sample surface is illustrated in Fig. 3. It is seen from Fig. 3 that the degree of deuteration monotonically decreases with time. However, experimental depth and time profiles, such as shown in Figs. 2(a), 2(b), and 3, cannot be described by the complimentary error function. This indicates that the $\mathrm{D} / \mathrm{H}$ proton exchange is not a simple Fick's diffusion process with the effective diffusion coefficient $D^{\text {eff }}$ independent of the deuteration degree. ${ }^{17}$

In order to extract the concentration dependence of $D^{e f f}$, we have preformed the Boltzmann analysis ${ }^{17,18}$ of the curves from Fig. 3. Time dependencies such as shown in Fig. 3 merge into one curve when replotted as a function of the Boltzmann variable $\eta=d / \sqrt{t}$ (where $d$

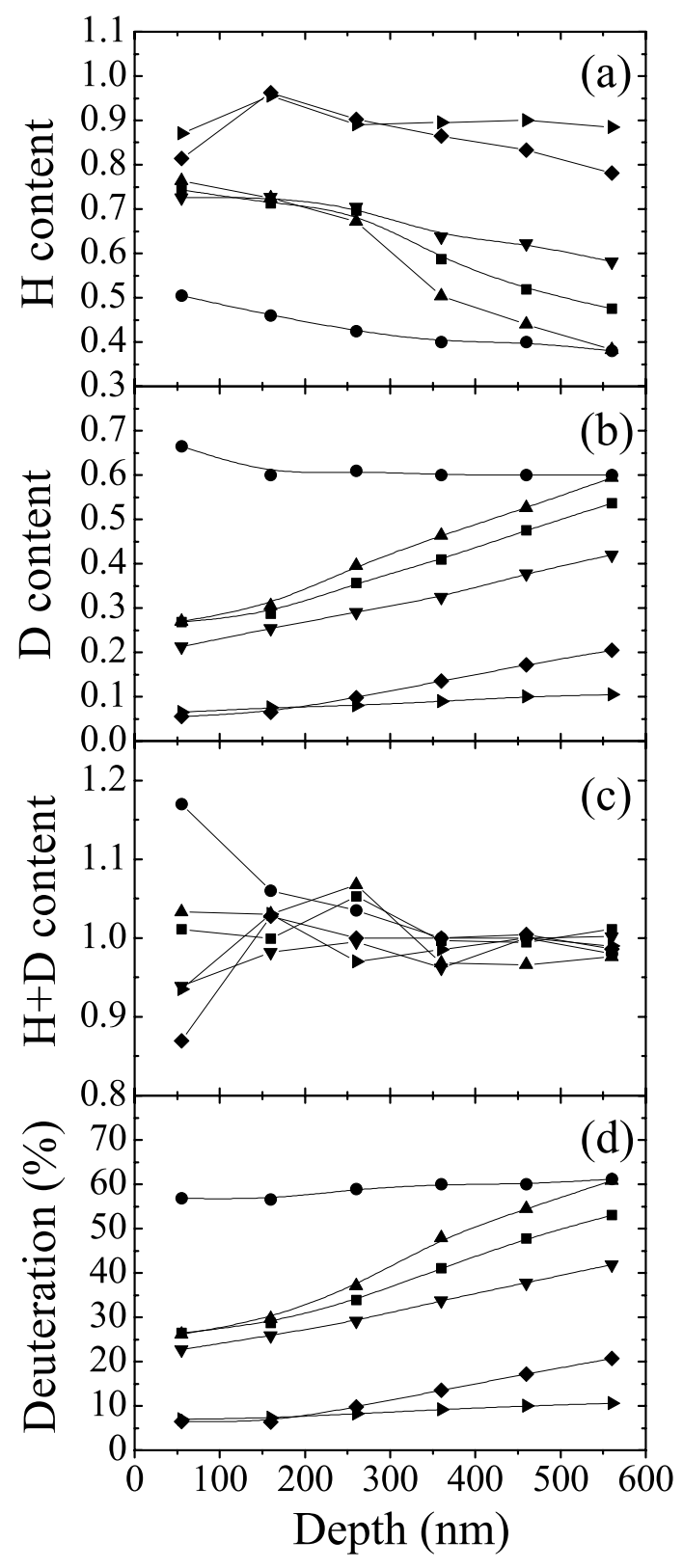

FIG. 2: Depth profiles of H and D content [(a) and (b)] as well as the total hydrogenation (c) and deuteration (d) of a $\mathrm{D}_{2} \mathrm{O}$-polished- $\mathrm{KD}_{1.2} \mathrm{H}_{0.8} \mathrm{PO}_{4}$ sample stored at ambient conditions for the following periods (in days): 1 (up triangles), 2 (squares), 4 (down triangles), 17 (diamonds), and 93 (right triangles). Profiles for $\mathrm{KD}_{1.2} \mathrm{H}_{0.8} \mathrm{PO}_{4}$ loaded into the vacuum chamber within $\sim 1$ minute after $\mathrm{D}_{2} \mathrm{O}$ polishing are shown by circles. 


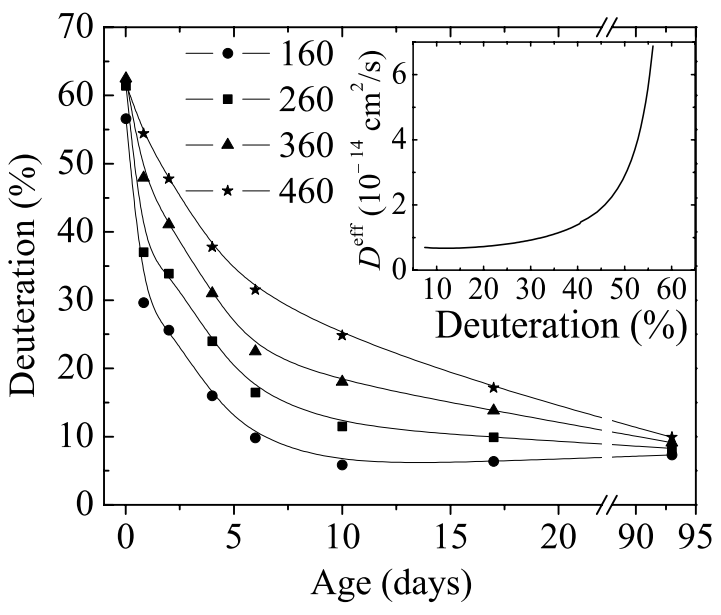

FIG. 3: Evolution of the deuteration degree of $\mathrm{KD}_{1.2} \mathrm{H}_{0.8} \mathrm{PO}_{4}$ stored at ambient conditions. Data are averaged over 100-nmthick layers at different depths from the sample surface, as indicated in the legend (in $\mathrm{nm}$ ). The inset shows the dependence of the effective diffusion coefficient $\left(D^{e f f}\right)$ on deuteration.

is the distance from the sample surface, and $t$ is time), and such an $x(\eta)$ curve can be used to extract the $D^{e f f}$ dependence. ${ }^{17}$ The inset in Fig. 3 shows the dependence of $D^{\text {eff }}$ on deuteration, obtained as a result of the Boltzmann analysis. ${ }^{17,18}$ It is seen from the inset in Fig. 3 that $D^{e f f}$ strongly decreases with a decrease in deuteration, which explains the fact that the depth profiles of $x$ and $y$, shown in Figs. 2(a) and 2(b), cannot be described by the complimentary error function.

Such a strong $D^{\text {eff }}(x)$ dependence also suggests that the $\mathrm{D} / \mathrm{H}$ exchange occurs via the proton tunneling mechanism. Indeed, in the case of tunneling, the proton transport through the lattice is expected to be exponentially dependent on the effective tunneling barrier. Be- cause the room-temperature lattice constants of DKDP increase (from $a=0.74529$ and $c=0.69751 \mathrm{~nm}$ up to $a=0.74697$ and $c=0.69766 \mathrm{~nm})$ with an increase in deuteration $x$ from 0 to 1 (Ref. 19), the corresponding decrease in the effective barrier for proton tunneling with an increase in deuteration can explain the strong $D^{\text {eff }}(x)$ dependence observed. However, the complex shape of the near-surface depth profiles of $\mathrm{H}$ and $\mathrm{D}$, as shown in Figs. 2(a) and 2(b), can also be related to possible lateral nonuniformities at a sub-millimeter scale, averaged during the ERDA analysis. At this stage, additional work is desirable to better understand the micromechanisms controlling the $\mathrm{D} / \mathrm{H}$ exchange in DKDP crystals.

Finally, it should be noted that the proton exchange effects described in detail above for one rapidly-grown $\mathrm{KD}_{1.2} \mathrm{H}_{0.8} \mathrm{PO}_{4}$ sample have also been observed for the other crystals studied (both rapidly- and conventionallygrown). However, we have found that crystals grown at different conditions are described by different $D^{\text {eff }}$. This can be attributed to variations in the types and concentrations of lattice defects and impurities for different conditions of crystal growth, and this effect requires additional systematic studies.

In conclusion, surface hydrogenation of rapidly-grown DKDP crystals stored at ambient conditions has been studied by ERDA. We have shown that the degree of deuteration in the $\sim 500$-nm-thick near-surface layer dramatically decreases due to the $\mathrm{D} / \mathrm{H}$ proton exchange. The effective diffusion coefficient depends on the deuteration degree and crystal growth conditions. This study have important implications for the estimation of the effects of surface preparation conditions and aging on the near-surface properties of DKDP.

Authors are grateful to S. Demos, G. Gilmer, T. Land, T. Huser, C. Hollars, and T. Suratwala, and P. Whitman for helpful discussions and for providing the samples investigated in this study. This work was performed under the auspices of the U.S. Department of Energy by the University of California, Lawrence Livermore National Laboratory under Contract No. W-7405-Eng-48.
1 See, for example, a review by D. Eimerl, Ferroelectrics 72, 95 (1987).

2 See, for example, a recent review by J. J. De Yoreo, A. K. Burnham, and P. K. Whitman, Internat. Mater. Rev. 47, 113 (2002), and references therein.

3 L. Chase, M. Runkel, S. G. Demos, J. J. De Yoreo, and W. J. Siekhaus, LLNL Internal Report No. NIF-0048735, 2000 (unpublished).

4 L. Chase, LLNL Internal Report No. NIF-0056984, 2000 (unpublished).

5 T. Huser, C. W. Hollars, W. J. Siekhaus, J. J. De Yoreo, T. Suratwala, and T. Land, LLNL Internal Memo, 2002 (unpublished).

6 See, for example, J. Tirira, Y, Serruys, and P. Trocellier, Forward Recoil Spectrometry (Plenum, NY, 1996).
7 S. G. Demos, M. Yan, M. Staggs, J. J. De Yoreo, and H. B. Radousky, Appl. Phys. Lett. 72, 2367 (1998).

${ }^{8}$ K. T. Stevens, N. Y. Garces, L. E. Halliburton, M. Yan, N. P. Zaitseva, J. J. De Yoreo, G. C. Catella, and J. R. Luken, Appl. Phys. Lett. 75, 1503 (1999).

9 R. G. Musket, R. S. Daley, and R. G. Patterson, Nucl. Instrum. Methods B 83, 425 (1993).

10 All ERDA spectra presented here were collected from fresh (i.e., previously unirradiated) areas of the sample. We have found that irradiation with $3 \mathrm{MeV} \mathrm{He}$ ions (during the ERDA analysis) effectively suppresses the $\mathrm{D} / \mathrm{H}$ exchange process, which we attribute to the effects of irradiationinduced lattice stress. Details of our study of this interesting effect will be reported separately.

11 L. R. Doolittle, Nucl. Instrum. Methods B 9, 344 (1985). 
12 Note that, for the scattering conditions used in this study, the strong nuclear resonance in the ${ }^{2} \mathrm{D}\left({ }^{4} \mathrm{He},{ }^{2} \mathrm{D}\right){ }^{4} \mathrm{He}$ crosssection (at a He ion energy of $\sim 2.14 \mathrm{MeV})^{13}$ appears in ERDA spectra at lower energies of $\mathrm{H}$ and $\mathrm{D}$ recoiled atoms than those shown in Fig. 1.

13 T. Lauritsen, T. Huus, and S. G. Nilsson, Phys. Rev. 92, 1501 (1953).

14 J. E. E. Baglin, A. J. Kellock, M. A. Crockett, and A. H. Shih, Nucl. Instrum. Methods B 64, 469 (1992).

15 A. J. Kellock and J. E. E. Baglin, Nucl. Instrum. Methods B 79, 493 (1993).
16 Details of our systematic study of the effect of surface polishing conditions on the surface hydrogenation of KDP and DKDP crystals will be reported elsewhere.

17 See, for example, J. Crank, The Mathematics of Diffusion (Oxford Univ., Oxford, 1975).

18 L. Boltzmann, Ann. Physik 53, 960 (1894).

19 W. R. Cook, Jr., J. Appl. Phys. 38, 163 (1967); C. Belouet, M. Monnier, and R. Crouzier, J. Cryst. Growth 30, 151 (1975). 